\title{
Um mapa de muitos caminhos
}

\author{
A map of many paths
}

\author{
Luciana Heymann \\ Professora, Centro de Pesquisa e Documentação de História Contemporânea do Brasil (CPDOC)/Fundação Getulio Vargas. \\ luciana.heymann@fgv.br
}

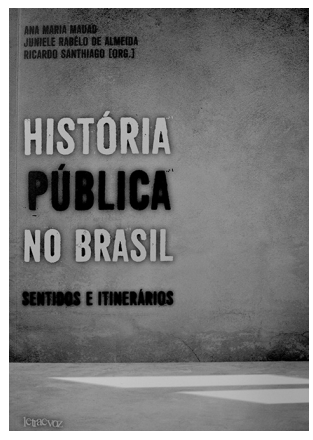

MAUAD, Ana Maria; ALMEIDA, Juniele Rabêlo de; SANTHIAGO, Ricardo (Org.). História pública no Brasil: sentidos e itinerários. São Paulo: Letra e Voz. 2016. 348p. $\bigcap^{s}$ s organizadores de História pública no Brasil: sentidos e itinerários o definem como um livro plural como o campo a que faz referência. A natureza da obra não poderia ser descrita de forma mais sintética e precisa, devendo-se essa pluralidade, em parte, ao fato de reunir textos apresentados nos dois simpósios internacionais promovidos pela Rede Brasileira de História Pública, em 2012 e 2014, além de outros produzidos especialmente para a publicação. Nesse sentido (um dos muitos do livro), a coletânea busca ser representativa com relação a um campo de debates nascente no país e dar inteligibilidade e organicidade a perspectivas multifacetadas que têm a história pública como objeto ou horizonte.

O livro reúne 25 textos, organizados em seis partes e um posfácio, e 29 autores, todos inseridos no campo acadêmico, sendo a franca maioria de historiadores. O caráter plural se refere, portanto, mais a temas e abordagens do que ao perfil dos colaboradores. A obra oferece vários itinerários de pesquisa e, ao mesmo tempo, distintos itinerários de leitura: uma história da história pública, as conexões entre história oral e história pública, história pública e novas tecnologias, história pública e patrimônio são alguns percursos transversais às seis partes que a estruturam. Para fazer jus à riqueza e à pluralidade do livro, optei por uma resenha que percorre os itinerários propostos pelos organizadores, dentro dos quais meu próprio percurso se desenhou.

O artigo de Ricardo Santhiago abre a primeira parte, "História pública: questões gerais". De maneira arguta, Santhiago toma a experiência brasileira no campo da história pública como eixo, invertendo a lógica de olhar a trajetória nacional à luz de outros desenvolvimentos. Trata-se de uma estratégia narrativa que recupera a historicidade do debate nacional e também de uma tomada de posição contra normatividades alheias ao campo que aqui se delineia nos últimos anos. Juntamente com os artigos de Michael Frisch e Linda Shopes, conforma-se um panorama geral de reflexões sobre o campo da história pública. Frisch amplia os contornos de seu conceito de "autoridade compartilhada", seduzido pelas potencialidades do gerenciamento 
digital de informações. Para explorá-las, adverte, uma "imaginação espacial não linear" seria necessária, tanto na catalogação de conteúdos como na promoção de interações entre usuários diferenciados. Shopes centra sua análise nas conexões entre história oral e história pública no contexto norte-americano, abordando convergências históricas, políticas e metodológicas entre os dois campos de atuação do historiador. Tais conexões se materializam no artigo de Juniele Rabêlo, que explora o tema a partir de suas pesquisas junto a movimentos sociais. As noções de compartilhamento e coprodução, presentes em Frisch e Shopes, são centrais ao seu argumento. O artigo de Renata Schittino assume, nesse conjunto, um caráter mais autônomo, uma vez que o interesse da autora é discutir a natureza e os significados da categoria "público". A partir de Hannah Arendt e Jürgen Habermas, Schittino propõe um debate conceitual fundamental para a prática da história pública.

Os três textos que compõem a parte dois, "História pública e o universo da criação", traçam itinerários de aproximação entre as pesquisas individuais das autoras e o tema do livro. Ana Mauad aproxima o trabalho da artista plástica Rosângela Rennó da história pública, entendida como "uma plataforma de observação das várias possibilidades de se elaborar representações históricas e refletir sobre suas condições de apropriação coletiva". Ao fazer de cada espectador um interlocutor na interpretação do passado, Rennó expandiria as possibilidades de consciência histórica sobre o presente. Mônica Kornis, em seu texto sobre a minissérie Agosto e o filme Getúlio, está interessada nas formas pelas quais o cinema e a televisão tornam pública a história, conferindo-lhe enquadramentos particulares. O substrato da narrativa dos dois produtos, segundo Kornis, é uma "pedagogia moral" calcada no indivíduo e seus valores, chaves para a interpretação do drama histórico. Por fim, Miriam Hermeto apresenta um projeto de extensão desenvolvido no Departamento de História da Universidade Federal de Minas Gerais (UFMG) sobre canção popular e ensino de história. A sugestão é refletir sobre possibilidades de diálogo entre saber acadêmico e saber escolar, e problematizar o lugar secundário conferido a outras linguagens, como a música, na produção de interpretações do passado.

Os quatro artigos reunidos em "História pública e as comunicações" enfocam a imprensa, o cinema, o meio digital e o rádio. Especificidades e potencialidades desses quatro meios de difusão são discutidas pelos autores, que dão atenção diferenciada à história pública. Marialva Barbosa apresenta o estado da arte desse conceito e aponta a limitação de associálo apenas à ampliação do público das narrativas históricas, crítica assumida, aliás, por vários autores. Barbosa levanta importante questão, certamente inspirada em seu próprio objeto de pesquisa, os jornais: qual a natureza do "público", entendido como arena e como audiência, no contexto contemporâneo de "virtualidade da existência"? Essa temática é enfrentada com maestria no artigo de Anita Lucchesi e Bruno Leal, que faz um esforço de conceituação e de historicização da história pública e da história digital. Esta última é apresentada como uma "arena aberta de debates e experimentações" que tem alterado substancialmente as dimensões de ensino, pesquisa e divulgação históricas, potencializando-as, mas também configurando novos e delicados desafios. O ponto de vista dos autores converge com o de Michael Frisch: o espaço digital é o ambiente mais propício à produção de uma história pública, menos pela acessibilidade aos conteúdos e mais pelas possibilidades de interatividade. O texto de Rodrigo Ferreira mapeia os estudos que conectam cinema, história pública e educação, inscrevendo-se 
no esforço de dar visibilidade a esse campo de discussão e a seus agentes. David Dunaway, ao discutir as tensões e desafios enfrentados pelo historiador-produtor (de programas de rádio e/ou podcasts), ilumina especificidades do trabalho de edição e seus riscos: o reducionismo, a mediação cultural e a tradução de conteúdos na "gramática da difusão", o que também reverbera reflexões de Mônica Kornis acerca da teledramaturgia.

Na parte quatro, dedicada às interfaces da história pública com a educação, os quatro capítulos parecem se relacionar dois a dois. Os textos de Everardo Paiva de Andrade e Nívea Andrade, de um lado, e Fernando Penna e Renata Silva, de outro, exploram a história escolar, entendida como saber diferenciado, resultado de práticas que se estabelecem na escola - espaço de articulação entre diferentes saberes e memórias. No texto de Penna e Silva, mais do que isso, a escola aparece como espaço público privilegiado e hoje ameaçado pelo projeto Escola sem Partido. Os textos de Thaís Fonseca e Sonia Wanderley abordam os usos que o ensino de história confere ao conhecimento produzido fora da academia, veiculado por meio de mídias, sejam as já tradicionais revistas de divulgação, sejam as novas mídias digitais. Wanderley vai além ao expor sua preocupação com as narrativas históricas produzidas pelo jornalismo e pela ficção quando conferem ao passado um caráter unívoco e definitivo, característico do senso comum. A autora sugere que o saber histórico escolar pode e deve funcionar como caução contra representações simplificadoras do passado.

Os três capítulos que compõem a parte cinco, "Políticas públicas e políticas culturais", têm em comum o fato de se debruçarem sobre a cultura popular e iniciativas públicas (aqui, no sentido de governamentais) que visam à sua proteção e valorização. O lugar do historiador nesses processos, porém, é tematizado apenas no capítulo de Hebe Mattos e Martha Abreu, não por acaso duas historiadoras com longa estrada na mediação de processos de reconhecimento de comunidades quilombolas e de valorização de suas manifestações culturais. Interessa especialmente a visibilidade dada pelo artigo à natureza multifacetada da colaboração entre historiadores e comunidades, e a variedades de produtos daí resultantes, de acervos de entrevistas a documentários e roteiros turísticos. O texto de Marta Rovai aparece, em certo sentido, como contraponto à potência evidenciada no artigo anterior, ao apontar para os riscos de "mercantilização" da cultura popular e para a ameaça de políticas públicas que desconsiderem os interesses das comunidades. Tanto o artigo de Rovai como o de Lia Calabre fazem um histórico das políticas públicas patrimoniais voltadas para a cultura popular. Calabre analisa os impactos de ações de patrimonialização do jongo sobre comunidades jongueiras - tanto o empoderamento dos grupos como a espetacularização de suas tradições. Esses artigos dialogam diretamente com o posfácio de José Newton Meneses. Após condensar o sentido geral da obra, Meneses toma o conceito de patrimônio histórico-cultural como ponto de apoio para pensar as interseções que marcam o campo das interpretações públicas do passado, destacando sua natureza interdisciplinar.

A última parte do livro, "Debates no espaço público: construindo histórias", abriga duas ordens de textos. Três historiadores analisam suas respectivas atuações em áreas não estritamente acadêmicas: Beatriz Kushnir avalia seu trabalho à frente do Arquivo Geral da Cidade do Rio de Janeiro, Benito Schmidt analisa uma experiência de curadoria de exposição e Jorge Ferreira discorre sobre as expectativas de um historiador-biógrafo com a recepção de sua obra, no caso, João Goulart: uma biografia. Dos três, retenho o artigo de Schmidt, pelas 
reflexões sobre os desafios que o historiador enfrenta para comunicar-se com públicos que têm visões de passado distintas daquelas conformadas pela disciplina histórica e para manter-se fiel aos princípios que orientam o ofício do historiador. Por fim, os artigos de Adriane Costa e Daphne Patai se articulam em torno da categoria intelectual público em dois contextos: a América Latina da década de 1960 e o universo acadêmico norte-americano contemporâneo. A justaposição dos artigos evidencia a historicidade da categoria e dos debates que suscita. Ao constatar o afastamento do intelectual público das querelas partidárias e mais propriamente políticas, características dos anos 1960, Costa indaga se os intelectuais teriam perdido sua "razão de existir". Em contraste, Patai critica a hipervisibilidade dos intelectuais públicos hoje e associa o engajamento intelectual na universidade à negação da responsabilidade docente. Ao criticar a valorização da "diversidade" e da "justiça social" (aspas no original) no ambiente universitário, Patai nega a associação entre universidade e espaço público. Trata-se de itinerário que segue na contramão de muitas contribuições do próprio livro, e que tem o mérito de nos lançar de novo no debate. Não deixa de ser uma maneira interessante de encerrar uma publicação que assume a pluralidade do campo como potência e desafio. História pública no Brasil: sentidos e itinerários é, sem dúvida, um mapa generoso de muitos caminhos.

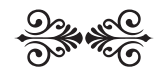

